Menna, M. E. DI (1959). J. gen. Microbiol. 20, 13-23

\title{
Some Physiological Characters of Yeasts from Soils and Allied Habitats
}

\author{
By MARGARET E. DI MENNA \\ Soil Bureau, Department of Scientific and Industrial Research, \\ Wellington, Nere Zealand
}

\begin{abstract}
Summary: An investigation has been made of some physiological properties of yeasts from soil and from the leaf surfaces of pasture plants. Almost all the species tested could use cellobiose, and the majority could synthesize growth factors and use a range of organic acids as carbon sources. Some species, including all the pigmented ones examined, could use aromatic compounds as carbon sources. A few species could liquefy gelatin. Only two were able to degrade pectin completely under the conditions used. Almost all could grow within a wide range of hydrogen ion concentrations and at osmotic pressures of at least 30 atmospheres. Ability to survive desiccation varied greatly. Only one species showed any ability to grow at low oxygen tensions. No marked or consistent differences could be seen between soil and leaf yeasts. As both groups are competent to grow in substrates which supply low concentrations of complex foodstuffs, it seems likely that antagonistic factors originating from other members of the soil and leaf populations are responsible for keeping the two floras distinct.
\end{abstract}

There appear to be relatively few species of yeasts which occur in important numbers in New Zealand soils (di Menna, 1955 a, 1957, 1958; A. C. S. Wright, to be published). An examination has been made of some of the physiological characters of these species in an attempt to discover what part they play in the organic cycle of soil, to find some of the limiting and predisposing factors which may influence their distribution, and to find the lines upon which more intensive research may best be followed. Some yeast species from the leaf surfaces (phyllosphere) of pasture plants (Lolium perenne, Trifolium repens, Anthoxanthum odoratum and Agrostis tenuis) are also included in the work. The species selected had been on one or several occasions the dominant yeast species in cultures from soil suspensions or leaf washings on acidified glucose peptone agar, or they had been frequently found in these habitats, although in smaller proportions. In addition, a number of species of uncertain habitat, but possibly of importance in a soil or phyllosphere flora were included in the work.

Schizoblastosporion starkeyi-henricii was dominant in three of five samples in one collection of soil (di Menna, 1957), but although samples were taken on a number of occasions from the same site it was never again found in large proportions and has been isolated only sporadically from other soils. About $\mathbf{2 0} \%$ of the air-borne yeasts collected in Dunedin, New Zealand (di Menna, 1954, 1955b) were Debaryomyces spp., mainly $D$. kloeckeri. The habitats of all the other common air-borne yeasts of these surveys were found to be soil or leaves. As it seems likely that one or both of these substrates will prove to be the source of Debaryomyces spp., representatives of two members of 
the genus were included in this work. Cryptococcus luteolus, Candida guilliermondii and Sporobolomyces pararoseus had appeared in cultures from soil and grass irregularly and in small numbers but sufficiently frequently to warrant inclusion in this work.

The yeasts examined were: from soil Saccharomyces delbrueckii Lindner, Cryptococcus albidus (Saito) Skinner, C. diffluens (Zach) Lodder \& Kreger-van Rij, C. terreus di Menna, Candida tropicalis (Cast.) Berkhout, C. humicola (Daszewska) Diddens \& Lodder, C. parapsilosis (Ashf.) Langeron \& Talice, C. curvata (Diddens \& Lodder) Lodder \& Kreger-van Rij, C. muscorum di Menna, Trichosporon pullulans (Lindner) Diddens \& Lodder, T. cutaneum (de Beurm., Gougerot \& Vaucher) Ota; from the phyllosphere Sporobolomyces roseus Kluyver \& van Niel, Cryptococcus laurentii (Kufferath) Skinner, Torulopsis ingeniosa di Menna, Rhodotorula glutinis (Fres.) Harrison, $\boldsymbol{R}$. mucilaginosa (Jorg.) Harrison, $\boldsymbol{R}$. graminis di Menna. Of uncertain habitat Debaryomyces hansenii (Zopf) Lodder \& Kreger-van Rij, D. kloeckeri Guill. \& Peju, Sporobolomyces pararoseus Olson \& Hammer, Cryptococcus luteolus (Saito) Skinner, Candida guilliermondii (Cast.) Langeron \& Guerra, Schizoblastosporion starkeyi-henricii Ciferri.

Usually two isolates of each species were examined. Only one isolate each of Debaryomyces hansenii, Sporobolomyces pararoseus, Cryptococcus luteolus, C. diffluens, Candida tropicalis, Trichosporon pullulans and Rhodotorula mucilaginosa was available for some or all of the tests. Species had been identified by the methods of Lodder \& Kreger-van Rij (1952). These authorities use routinely in their identifications the fermentation of glucose, sucrose, maltose, lactose, galactose and raffinose, and the assimilation of glucose, sucrose, maltose, lactose, galactose and potassium nitrate. Production of starch-like compounds was also looked for in certain groups. The term 'fermentation' as used here means the production of acid and of gas in large enough quantities to be trapped in a Durham tube. The fermenting species studied were Saccharomyces delbrueckii, Candida tropicalis, C. guilliermondii and C. parapsilosis. 'Pigmented species' referred to later in this work were the species of Sporobolomyces and Rhodotorula used.

The physiological characters studied were:

(1) Physico-chemical. The limits of hydrogen-ion concentration, osmotic pressure and oxygen tension within which growth occurred, and ability to survive desiccation.

(2) Nutritional; ability to use organic acids, aromatic compounds, cellobiose and cellulose as sole carbon sources; pectinolytic and amylolytic activity; proteolytic activity; effects of decreasing the concentration of $(a)$ carbon source, $(b)$ nitrogen source, $(c)$ growth factors, and $(d)$ mineral nutrients.

\section{METHODS}

Two-day-old cultures on glucose peptone agar were used for inoculations. All cultures were incubated at room temperature. Two media were used extensively, glucose yeast extract broth (Kurung, 1942) and the liquid auxanographic medium of Lodder \& Kreger-van Rij (1952, p. 25). 


\section{Physico-chemical tests}

Hydrogen-ion concentration. The $\mathrm{pH}$ values of three batches of glucose yeast extract broth was adjusted by the addition of $\mathrm{N}-\mathrm{HCl}$ to $\mathrm{pH} \mathrm{2,3}$ and 4 . The $\mathrm{pH}$ of three batches of peptone water $(1 \%, w / v$, peptone, British Drug Houses Ltd., in tap water) was adjusted with $\mathrm{NaOH}$ to values of 8,9 and 10, glucose yeast extract broth having proved unsuitable in this range. Results were read a week after inoculation for $\mathrm{pH}$ values of $2,3,4$, and at 3 days after inoculation for values of 8,9 and 10 .

Osmotic pressure. Glucose yeast extract broth at $\mathrm{pH} 4$ was made up without $\mathrm{NaCl}$. The broth was assumed to have an osmotic pressure of $c .5$ atmospheres (8 g. glucose/l. distilled water gives a calculated osmotic pressure of 1 atmosphere). Glucose was added to give media with calculated osmotic pressures of 10, 20, 30, 40,60, 80 and 100 atmospheres. A second series of media was prepared in which $\mathrm{NaCl}$ was added to give calculated osmotic pressures of $10,20,30,40,60$ and 80 atmospheres. $2 \cdot 6 \mathrm{~g}$. $\mathrm{NaCl} / \mathrm{l}$. distilled water was taken to give an osmotic pressure of 1 atmosphere. Cultures were incubated for a week before the results were read.

Oxygen tension. Two media were used: (a) $1 \%$, w/v, peptone in tap water solidified with agar ( $1 \%$, w/v, agar, Davis (N.Z.) Ltd., standard grade); (b) $15 \%, \mathrm{w} / \mathrm{v}$, gelatin, Davis (N.Z.) Ltd., in tap water. The tubed medium was melted, cooled to $c .45^{\circ}$, inoculated, and mixed by rolling without shaking to avoid inclusion of air. Cultures were incubated for 2 weeks; ability to grow at decreased oxygen tensions was measured by the depth to which growth had occurred.

Desiccation. Yeasts in sterile tap water were dropped on sterile filter-paper disks and dried out at room temperature in a dark, well-ventilated cupboard without the use of desiccants. The disks appeared dry in a week and were stored in air-tight containers. Viability was tested by incubating a disk in a tube of glucose yeast extract broth, at first at weekly intervals, but later at two-weekly, and finally at monthly intervals. A yeast was considered no longer viable when three successive cultures were sterile.

\section{Nutritional tests}

Use of carbon sources. Liquid 'auxanographic' medium in which glucose was replaced by the carbon compounds to be tested was used for this series of experiments. The organic acids used (see Table 2) were added in $0 \cdot 1 \%(\mathrm{w} / \mathrm{v})$ concentration, the medium brought to $\mathrm{pH} 4-5$ with $\mathrm{NaOH}$ and sterilized by autoclaving at $15 \mathrm{lb} . / \mathrm{sq} . \mathrm{in}$. for $15 \mathrm{~min}$. The volatile aromatic compounds, ferulic acid and $p$-hydroxybenzaldehyde (L. Light and Co.) and vanillin (British Drug Houses Ltd., A.R.), which are products resulting from the degradation of lignin, were added to the sterile basal medium in $0.01 \%(\mathrm{w} / \mathrm{v})$ concentration and left for some weeks to test sterility before dispensing and inoculating. Cellulose and cellobiose were added to $0.5 \%$ concentration, the medium solidified with $2 \%$ agar and sterilized by autoclaving. Solidification of this series was necessary because of the particulate nature of cellulose 
powder. Control tubes of basal medium without a carbon source were inoculated in each series of cultures. All results were read after incubation for 2 weeks.

Proteolytic activity. Proteolytic activity was tested with gelatin and egg albumin. The $15 \%$ gelatin tubes used for detection of growth at decreased oxygen tensions were incubated for 4 weeks and examined for proteolysis.

Egg albumin slopes were prepared as follows: egg flake albumin (British Drug Houses, Ltd.) $7 \cdot 5 \%(\mathrm{w} / \mathrm{v})$; glucose $1 \% ; \mathrm{KH}_{2} \mathrm{PO}_{4} 0 \cdot 1 \%$, in tap water, mixed, dispensed in tubes, and steamed in a sloping position for $20 \mathrm{~min}$. on 2 successive days. Cultures on these were incubated for 3 weeks.

Amylolytic activity. Soluble starch (British Drug Houses, Ltd., A.R.) was added to $0.2 \%(\mathrm{w} / \mathrm{v})$ concentration to $1 \%$ peptone water. Three weeks after inoculation the cultures were tested with iodine for disappearance of starch. A parallel series of cultures was made on the medium of Mager \& Aschner (1947) to test the production of starch-like compounds.

Pectinolytic activity. Use was made of the property of both pectin and pectic acid solutions to form a clot when mixed with ethanol. A pectin-containing medium was made as follows: minced New Zealand grapefruit were soaked overnight in three times their weight of water, boiled next day for $2 \mathrm{hr}$., and filtered through muslin. The filtrate was brought to $\mathrm{pH} 4$ with $\mathrm{NaOH}$, dispensed and sterilized by steaming for 20 min. on 3 successive days. After incubation for 6 weeks an equal volume of ethanol was added to the cultures. Absence of a gel indicated pectinolysis.

\section{Effect of decreasing the concentration of nutrients}

Carbon and nitrogen sources. Two series of auxanographic media solidified with agar $(2 \%, \mathrm{w} / \mathrm{v})$ were prepared. In one series six concentrations of the carbon source (glucose) were used: $0.5 \%$ (standard), $0 \cdot 2,0 \cdot 1,0 \cdot 05,0.01 \%$ and nil. In the second series the concentration of the nitrogen source (ammonium sulphate) was varied: $0.5 \%$ (standard), 0.2, 0.05, 0.01, 0.0025\% and nil. Inoculations were made by placing drops of the yeast suspensions upon the agar slopes in as uniform a manner as possible. Cultures were incubated for 2 weeks and the amount of growth read visually.

Mineral nutrients. The proportions of the mineral nutrient mixture in the liquid auxanographic medium was decreased from standard to $1 / 10$ standard, 1/100, 1/1000 and nil. Particular care was taken with this series to avoid mineral contamination. All chemicals used were 'Analar' grade. Glassware was cleaned with chromic-sulphuric acid mixture and given a final rinse with triple glass-distilled water. Test tubes $18 \mathrm{~mm}$. in diameter containing $10 \mathrm{ml}$. of the medium were plugged with cotton wool wrapped in Whatman's No. 50 filter-paper to prevent possible mineral contamination via cotton fibres. The cultures were incubated for 2 weeks. The optical density was measured with a Spekker photoelectric absorptiometer, using Kodak No. 5 yellow-green filters. Cultures of Candida humicola and Trichosporon cutaneum, which had granular growth forms, were homogenized with a tissue grinder before readings were made. 
Growth factors. Concentration of the growth factor mixture in the liquid auxanographic medium was decreased from the standard to 1/10 standard, 1/1000 standard and nil. The optical densities of growth were measured visually.

\section{RESULTS}

\section{Physico-chemical tests (Table 1)}

Hydrogen ion concentration. All the yeasts tested grew in broth at $\mathrm{pH}$ values of 4 to 8 ; the majority grew at values of 3 and 10 , but very few were capable of growth at $\mathrm{pH} 2$. Candida tropicalis, C. humicola, C. guilliermondii and Rhodotorula mucilaginosa grew at all $\mathrm{pH}$ values tested. There was little or no variation amongst isolates of the same species.

Table 1. Effects of some physico-chemical factors upon yeasts

\begin{tabular}{|c|c|c|c|c|}
\hline \multirow[b]{2}{*}{ From soil } & \multirow[b]{2}{*}{$\begin{array}{l}\text { pH within } \\
\text { which growth } \\
\text { occurred }\end{array}$} & \multicolumn{2}{|c|}{$\begin{array}{l}\text { Greatest osmotic } \\
\text { pressure in which } \\
\text { growth occurs }\end{array}$} & \multirow{2}{*}{$\begin{array}{l}\text { Duration of } \\
\text { viability of } \\
\text { desiccated } \\
\text { cultures } \\
\text { (weeks) }\end{array}$} \\
\hline & & $\begin{array}{l}\text { Produced } \\
\text { by glucose } \\
\text { (atm.) }\end{array}$ & $\begin{array}{c}\text { Produced } \\
\text { by NaCl } \\
\text { (atm.) }\end{array}$ & \\
\hline Saccharomyces delbrueckii & $3-8$ & 60 & 30 & 8-10 \\
\hline Cryptococcus albidus & $2-8$ & 30 & $\mathbf{3 0}$ & 4- 8 \\
\hline C. diffluens & $3-10$ & 40 & 20 & Over 37 \\
\hline C. terreus & $3-8$ & 40 & $\mathbf{3 0}$ & Over 37 \\
\hline Candida tropicalis & $2-10$ & 60 & 40 & 4 \\
\hline C. humicola & 2-10 & 60 & $\mathbf{3 0}$ & $2-3$ \\
\hline C. curvata & $2-8$ & 30 & 30 & $\overline{7}$ \\
\hline C. muscorum & $3-10$ & 60 & 40 & $3-18$ \\
\hline Trichosporon pullulans & $4-10$ & 40 & 30 & $\mathbf{8}$ \\
\hline T. cutaneum & 4-10 & 40 & 10 & 4 \\
\hline \multicolumn{5}{|l|}{ From phyllosphere } \\
\hline Cryptococcus laurentii & $4-9$ & 30 & 20 & 12 \\
\hline Torulopsis ingeniosa & $3-9$ & 30 & 20-30 & $\mathbf{3}$ \\
\hline Rhodotorula glutinis & $3-9$ & 60 & 30 & $\mathbf{8 - 2 0}$ \\
\hline R. mucilaginosa & $2-10$ & 60 & 40 & $>37$ \\
\hline R. graminis & $3-10$ & 60 & 40 & 32 \\
\hline \multicolumn{5}{|l|}{ Miscellaneous } \\
\hline Debaryomyces hansenii & 4-9 & 80 & 60 & 8 \\
\hline D. kloeckeri & $3-10$ & 80 & 60 & $7-16$ \\
\hline Sporobolomyces pararoseus & $3-9$ & 60 & 40 & 32 \\
\hline Cryptococcus luteolus & $3-8$ & 30 & 30 & $\mathbf{3}$ \\
\hline Candida guilliermondii & $2-10$ & 80 & 60 & $13-18$ \\
\hline $\begin{array}{l}\text { Schizoblastosporion starkeyi- } \\
\quad \text { henricii }\end{array}$ & $3-8$ & 20 & 10 & $\mathbf{0}$ \\
\hline
\end{tabular}

Osmotic pressure. There was much variation in the ability of the different species tested to grow in solutions of high osmotic pressure, but little variability within species. The fermenting and pigmented species included were able to grow at higher salt and glucose concentrations than the colourless and non-fermenting species. Schizoblastosporion starkeyi-henricii was particularly 
sensitive, failing to grow at pressures above 20 atmospheres in glucose and 10 atmospheres in salt. Almost all species were more sensitive to calculated osmotic pressures produced with salt than with glucose.

Oxygen tension. None of the species was able to grow in the depths of the gelatin tubes; Saccharomyces delbrueckii produced a zone of growth to a depth of $8 \mathrm{~mm}$. below the surface of the medium, the others grew to a depth of 2-5 $\mathrm{mm}$. In the peptone agar $S$. delbrueckii grew to a depth of $5 \mathrm{~mm}$. below the surface. Candida humicola and Trichosporon pullulans produced some mycelial tufts in the depths of the peptone agar; the growth of other species was restricted to the surface or to immediately beneath the surface.

Desiccation. There was considerable variation in resistance to desiccation amongst species and amongst isolates of the same species. All isolates of Cryptococcus diffluens, C. terreus and Rhodotorula mucilaginosa were viable after storage for 9 months. Sporobolomyces pararoseus and Rhodotorula graminis survived for 8 months in the dry state. No viable cultures were obtained from Schizoblastosporion starkeyi-henricii after drying.

Nutritional tests (Tables 2 and $\mathbf{3}$ )

$U$ se of carbon sources. No yeast tested was able to use cellulose as a carbon source. All but Saccharomyces delbrueckii and Schizoblastosporion starkeyi-henricii used cellobiose. All used glutamic acid and almost all used acetic, fumaric, $\alpha$-keto glutaric, gluconic, citric and succinic acids; only Saccharomyces delbrueckii, Trichosporon cutaneum and Schizoblastosporion starkeyi-henricii or some isolates of these species failed to grow. No yeast used maleic or oxalic acid under the conditions imposed. There was considerable variety in reaction to tartaric, lactic and oxaloacetic acids. Of the species tested, only Trichosporon cutaneum showed much variability in assimilation of organic acids; besides the two isolates used for all tests, five other isolates of $T$. cutaneum were grown on the acids, and of the seven, three used all but maleic and oxalic acids, and the remaining four gave erratic assimilation patterns. Van Uden \& Do Carmo Sousa (1957) found a similarly variable response of T. cutaneum to soluble starch, mannitol, inositol and sorbitol, and concluded that the species must be heterogeneous.

Torulopsis ingeniosa, Candida muscorum, Trichosporon pullulans and all the pigmented yeasts tested (with the exception of one isolate of Rhodotorula glutinis which will be discussed later) used vanillin, ferulic acid and $p$-hydroxybenzaldehyde. A few other non-fermenting yeasts used one or two of these compounds.

Proteolytic activity. None of the species tested was able to liquefy egg albumin although all grew well on it. Torulopsis ingeniosa and Candida muscorum liquefied gelatin rapidly (within a week), Trichosporon cutaneum, $T$. pullulans and Sporobolomyces roseus slowly, and Cryptococcus diffluens and Rhodotorula graminis slowly and variably. No odour accompanied the liquefaction of gelatin.

Pectinolytic activity. Torulopsis ingeniosa and Candida humicola were the only species which broke down the pectin preparation completely; all species 
grew well on the medium. Wieringa (1956), using a test for pectin hydrolysis which did not demand complete breakdown, reported that Cryptococcus albidus and Rhodotorula glutinis were pectinolytic. Bell \& Etchells (1956) stated that twenty of sixty-one yeasts species and varieties were capable of de-esterifying citrus pectin. Pectinolysis is of obvious importance in the breakdown of

Table 2. Organic acids used by yeasts

None of the species tested used maleic or oxalic acids; all used glutamic.

From soil

Acetic Citric Fumaric $\begin{gathered}\text { Gluco- } \\ \text { nic } \\ \text { glutaric Lactic acetic Succinic Tartaric }\end{gathered}$

Saccharomyces delbrueckii

Cryptococcus albidus

C. diffluens

C. terreus

Candida tropicalis

C. humicola

C. parapsilosis

C. curvata

C. muscorum

Trichosporon pullulans

T. cutaneum

$\begin{array}{llll}+ & + & - & + \\ + & + & + & + \\ + & + & + & + \\ + & + & + & + \\ + & + & + & + \\ + & + & + & + \\ + & + & + & + \\ + & + & + & + \\ + & + & + & + \\ + & + & + & + \\ + & \pm & \pm & \pm\end{array}$

$\begin{array}{lll}+ & - & + \\ + & + & - \\ + & + & - \\ + & + & - \\ + & + & + \\ + & + & + \\ + & + & + \\ + & + & + \\ + & + & + \\ + & + & + \\ \pm & \pm & +\end{array}$

$\begin{array}{llll}+ & \pm & - & - \\ - & - & + & + \\ - & - & + & \pm \\ - & - & + & \pm \\ + & - & + & + \\ + & + & + & + \\ + & + & + & + \\ + & + & + & + \\ + & - & + & + \\ + & - & + & + \\ + & \pm & + & \pm\end{array}$

From phyllosphere

Sporobolomyces roseus

Cryptococcus laurentii

Torulopsis ingeniosa

Rhodotorula glutinis

R. mucilaginosa

R. graminis

Miscellaneous

Debaryomyces hansenii

D. kloeckeri

Sporobolomyces pararoseus

Cryptococcus luteolus

Candida guilliermondii

Schizoblastosporion

starkeyi-henricii

$\begin{array}{lllll} & & & & \\ + & + & + & + \\ + & + & + & \pm \\ + & + & + & + \\ + & + & + & + \\ + & + & + & + \\ + & + & + & +\end{array}$

$\begin{array}{llllll}+ & + & + & + & + & + \\ + & + & + & + & + & + \\ + & + & + & + & + & + \\ + & + & + & + & + & - \\ + & + & + & + & + & + \\ \pm & - & + & + & + & -\end{array}$

+
-
+
+
+
+
+
+
+
+
+

$\pm=$ Reaction varies with isolate.

plant materials in the soil, pectinolytic organisms probably being primary invaders (Wieringa, 1955). Further work is needed to demonstrate the presence or absence of pectinases in soil and leaf yeasts.

Amylolytic activity. None of the fermenting yeasts used all the soluble starch in the medium, but a large proportion of the other soil and leaf yeasts caused its complete disappearance. Amylolytic activity was not always correlated with starch synthesis, neither did the reverse necessarily apply.

\section{Effect of decrease in concentration of nutrients}

Carbon and nitrogen sources. The method used was one which could be expected to reflect only gross differences in demand for these nutrients; no such differences were seen. After 2 weeks of incubation all species tested showed as abundant growth on solid auxanographic medium with $\mathbf{0 . 2}$ and 
$0.05 \%$ ammonium sulphate as upon the standard with $0.5 \%$. Growth upon the medium with $0.01 \%$ ammonium sulphate was only a little decreased, and was still considerable with $0.0025 \%$ (25 p.p.m.) of ammonium sulphate added, but the agar used to solidify the medium added a further 4 p.p.m. (Dr D. J. Ross, personal communication).

\section{Table 3. Some nutritional characters of yeasts}

The nutritional rating is the sum of tests positive in Tables 2 and 3. Starch synthesis and use of nitrate nitrogen are not included in the rating.

From soil
Saccharomyces delbrueckii
Cryptococcus albidus
C. diffluens
C. terreus
Candida tropicalis
C. humicola
C. parapsilosis
C. curvata
C. muscorum
Trichosporon pullulans
T. cutaneum
From phyllosphere
Sporobolomyces roseus
Cryptococcus laurentii
Torulopsis ingeniosa
Rhodotorula glutinis
R. mucilaginosa
R. graminis
Miscellaneous
Debaryomyces hansenii
D. kloeckeri
Sporobolomyces pararoseus
Cryptococcus luteolus
Candida guilliermondii
Schizoblastosporion
starkeyi-henricii

From soil

Saccharomyces delbrueckii

C. diffuens

C. terreus

C. parapsilosis

C. curvata

Trichosporon pullulans

T. cutaneum

rom phyllosphere

Cryptococcus laurentii

Torulopsis ingeniosa

Rhodotorula glutinis

R. graminis

Miscellaneous

ces hansenii

Cryptococcus luteolus

Schizoblastosporion

starkeyi-henricii
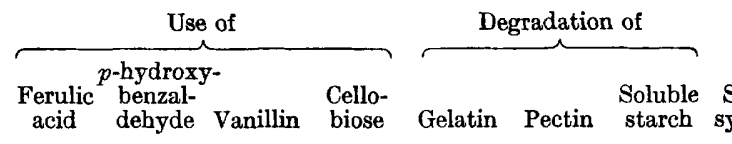

$\begin{array}{llll}- & - & - & - \\ + & - & - & + \\ \pm & - & - & + \\ + & + & - & + \\ - & - & - & + \\ - & + & - & + \\ - & - & - & + \\ + & + & - & + \\ + & + & + & + \\ - & + & + & +\end{array}$

$\begin{array}{ll}- & - \\ \pm & - \\ = & - \\ - & - \\ - & + \\ - & - \\ + & - \\ + & - \\ + & -\end{array}$

Decrease in concentration of glucose in the auxanographic medium was followed by a more rapid decrease in growth, which again did not seem to vary among the species tested. After 2 weeks of incubation growth was detectably less at a glucose concentration of $0.1 \%$ than at the standard $0.5 \%$. There was a further decrease in the amount of growth at a concentration of $0.05 \%$ and only weak growth at $0.01 \%$ (100 p.p.m.). With no added available carbon source growth was lacking or only just detectable.

Mineral nutrients ('Table 4). Results from this set of experiments are difficult to interpret. Almost all isolates showed some drop in amount of growth when the concentration of the mixture of mineral nutrients was decreased to 1/10 standard. It seems that under the conditions in which the cultures were grown, the standard concentration of one or several of the minerals supplied was optimal or sub-optimal in respect to the proportions of carbon, nitrogen and growth factors. Although there was tolerably good agreement in reaction between different isolates of some species, other species showed such variability between isolates that interspecific comparisons do not seem justifiable. 
Part of the variations may have been due to authentic isolate differences in demand for minerals, part to mineral contamination of the cultures. A good deal of the variability seemed due to differences in amount of surface growth and consequent differences in oxygen supply. Use of culture vessels with a larger ratio of surface area:volume might overcome part of this, but more consistent results would probably be obtained by use of shaken cultures (Gavin, 1957).

Table 4. Effect upon growth of decrease of mineral nutrients in the defined medium

Figures in column headed 'standard' are drum readings from a Spekker photoelectric absorptiometer; figures in other columns are drum readings expressed as a percentage of the reading under 'standard'. A cell $0.25 \mathrm{~cm}$. deep was used for readings from cultures in media with standard and 1/10 standard mineral nutrients. A $1 \mathrm{~cm}$. cell was used for readings from the less dense cultures in media with $1 / 100,1 / 1000$ and no mineral nutrients; these were divided by four before calculating the percentage figures shown.

\begin{tabular}{|c|c|c|c|c|c|}
\hline \multirow[b]{2}{*}{ From soil } & \multicolumn{5}{|c|}{ Concentration of mineral nutrients } \\
\hline & Standard & $\begin{array}{l}1 / 10 \\
(\%)\end{array}$ & $\begin{array}{c}1 / 100 \\
(\%)\end{array}$ & $\begin{array}{c}1 / 1000 \\
(\%)\end{array}$ & $\begin{array}{c}\text { None } \\
(\%)\end{array}$ \\
\hline \multirow[t]{2}{*}{ Saccharomyces delbrueckii } & $0 \cdot 475$ & 50 & 4 & 1 & 1 \\
\hline & $0 \cdot 480$ & 49 & 8 & 1 & 1 \\
\hline \multirow[t]{2}{*}{ Cryptococcus albidus } & $0 \cdot 233$ & 92 & 79 & 49 & 15 \\
\hline & 0.231 & - & 74 & 33 & $\mathbf{3}$ \\
\hline C. diffluens & $0 \cdot 133$ & 57 & 48 & 23 & 4 \\
\hline \multirow[t]{2}{*}{ C. terreus } & $0 \cdot 182$ & 104 & 62 & 10 & 4 \\
\hline & $0 \cdot 210$ & 71 & 56 & 19 & $\mathbf{2}$ \\
\hline Candida tropicalis & $0 \cdot 699$ & 94 & 30 & 12 & 6 \\
\hline \multirow[t]{2}{*}{ C. humicola } & $0 \cdot 450$ & 82 & 55 & 25 & 4 \\
\hline & 0.538 & 65 & 34 & 18 & 4 \\
\hline \multirow[t]{2}{*}{ C. curvata } & $0 \cdot 281$ & 95 & 67 & $\mathbf{3 0}$ & 8 \\
\hline & $0 \cdot 342$ & 75 & 53 & 33 & 14 \\
\hline \multirow[t]{2}{*}{ C. muscorum } & 0.883 & 117 & 19 & 11 & 8 \\
\hline & 0.957 & 99 & 22 & 9 & 6 \\
\hline Trichosporon pullulans & $0 \cdot 188$ & 70 & 63 & 15 & 4 \\
\hline \multirow[t]{2}{*}{ T. cutaneum } & $0 \cdot 247$ & 48 & $\mathbf{3 6}$ & 9 & 2 \\
\hline & $0 \cdot 237$ & 76 & 43 & 13 & 3 \\
\hline \multicolumn{6}{|l|}{ From phyllosphere } \\
\hline \multirow[t]{2}{*}{ Cryptococcus laurentii } & $0 \cdot 420$ & $\mathbf{5 1}$ & 26 & 8 & 1 \\
\hline & $0 \cdot 210$ & 85 & 65 & 25 & 2 \\
\hline \multirow[t]{2}{*}{ Torulopsis ingeniosa } & $0 \cdot 278$ & 98 & 62 & 21 & 2 \\
\hline & $0 \cdot 437$ & 56 & 40 & $\mathbf{2}$ & 1 \\
\hline \multirow[t]{2}{*}{ Rhodotorula glutinis } & $0 \cdot 201$ & 83 & 78 & 12 & $\mathbf{2}$ \\
\hline & 0.490 & 73 & $\mathbf{5 3}$ & 23 & 7 \\
\hline R. mucilaginosa & $0 \cdot 204$ & 73 & 67 & 36 & 15 \\
\hline \multirow{2}{*}{ R. graminis } & 0.752 & 92 & 23 & 13 & $\mathbf{2}$ \\
\hline & 0.769 & 89 & 24 & 10 & 1 \\
\hline \multicolumn{6}{|l|}{ Miscellaneous } \\
\hline \multirow{3}{*}{$\begin{array}{l}\text { Debaryomyces hansenii } \\
\text { D. kloeckeri }\end{array}$} & $0 \cdot 250$ & 80 & 62 & 16 & 2 \\
\hline & $0 \cdot 224$ & 73 & 52 & 16 & 2 \\
\hline & $0 \cdot 272$ & 93 & 49 & $\mathbf{2 3}$ & 4 \\
\hline Sporobolomyces pararoseus & $0 \cdot 712$ & 87 & 17 & 9 & 1 \\
\hline \multirow{3}{*}{$\begin{array}{l}\text { Cryptococcus luteolus } \\
\text { Candida gulliermondii }\end{array}$} & $0 \cdot 198$ & 89 & 70 & 42 & 3 \\
\hline & $0 \cdot 418$ & 86 & 45 & 22 & $\mathbf{1}$ \\
\hline & 0.772 & 73 & 22 & 11 & - \\
\hline \multirow{2}{*}{$\begin{array}{c}\text { Schizoblastosporion } \\
\text { starkeyi-henricii }\end{array}$} & $0 \cdot 156$ & 83 & 12 & 6 & 6 \\
\hline & $0 \cdot 100$ & 81 & 10 & 1 & $\mathbf{5}$ \\
\hline
\end{tabular}


Growth factors. There were differences in response to decreased concentrations of the standard growth factor mixture. All isolates produce as dense growth at 1/10 standard concentration as at standard. Some species, none of which could use nitrate nitrogen, grew only slightly when the concentration was decreased to $1 / \mathbf{1 0 0 0}$, and very slightly or not at all with no added growth factors. Of the species which could not use nitrate nitrogen, only Sporobolomyces pararoseus and Candida tropicalis were able to synthesize growth factors. All species which could assimilate nitrate nitrogen were able to grow without added growth factors except for one isolate of Rhodotorula glutinis. This isolate was aberrant in other ways, being unable to use any of the aromatic compounds tested as carbon sources, nor could it use tartaric acid, but it survived desiccation for 20 weeks, whilst the other isolate used was viable for only 8 weeks. It did not seem to be a commonly occurring variant, for three additional isolates tested used the aromatic compounds and synthesized growth factors, four additional isolates assimilated tartaric acid, and of a total of eight isolates, all of which could split soluble starch, it was the only one which could also synthesize a starch on Mager \& Aschner's medium. Skinner \& Huxley (1956), who noted a correlation between use of nitrate nitrogen and synthesis of growth factors, reported that all the five isolates of $\boldsymbol{R}$. glutinis which they used grew in a vitamin-free medium.

\section{DISCUSSION}

In an attempt to summarize the results of the nutritional tests, the species examined have been given ratings (Table 3); one point was given for each test positive in Tables 2 and 3, except for use of nitrate nitrogen and for starch synthesis, and the sum of the points was the rating. Where a reaction was variable half a point was given, and where all species tested gave a positive result no points were given. It is realized that the tests applied were of unequal significance; ability to synthesize growth factors doubtless confers greater advantage than ability to assimilate one of a series of organic acids, but it seems impossible to assess the value of the characters more precisely.

On the whole the species isolated consistently as dominants (i.e. dominant yeasts) from the soil and from the phyllosphere of pasture plants, had higher ratings than those included in the miscellaneous group, species which have not yet been found as dominants on vegetation or in soil. Almost all the species which could synthesize growth factors and assimilate aromatic compounds, and which had amylolytic, pectinolytic or proteolytic powers, are included in the soil and phyllosphere groups.

The work done has shown that the yeasts which are common in the soil and the phyllosphere are equipped to use foodstuffs which may occur in these habitats. Some other species, less common in these places, but still numerous enough to appear relatively frequently in population samples, have lesser catabolic powers, as indicated by lower ratings. Except for those species which can degrade pectin, it does not seem likely that soil and phyllosphere yeasts play a primary part in the breakdown of vegetable matter, but rather that 
they follow organisms which attack cellulose and lignin and that they use the resulting degradation products.

The tests applied show no consistent differences between soil and phyllosphere species, yet in the field these two groups are distinct. In surveys made so far soil yeasts have rarely been found upon the leaves of pasture plants, and although phyllosphere yeasts do invade the upper layers of the soil, particularly in summer when numbers on leaves are very high, they do not persist. It is possible that the wrong techniques have been used to show why one species can and does live in soil and another on leaves. One of the limitations of this work is the lack of precise information about the foodstuffs present and available in soil and on plant leaves. Garrett (1957) has written: 'The complex interlocking social structure of most natural communities is determined first by the selective action of the habitat and secondly by the interactions of its inhabitants.' The selective action of the habitats, a rather low but perhaps fairly constant concentration of somewhat complex foodstuffs, would explain the physiological similarities between soil and leaf yeasts; the interactions of the inhabitants may explain why the two yeast populations are distinct.

Soil Bureau Publication No. 143.

\section{REFERENCES}

Bell, T. A. \& Etchells, J. L. (1956). Pectin hydrolysis by certain salt-tolerant yeasts. Appl. Microbiol. 4, 196.

GARRETT, S. D. (1957). Ecologists in the laboratory. Nature, Lond. 180, 351.

Gavin, J. J. (1957). Analytical microbiology. III. Turbidometric methods. Appl. Microbiol. 5, 235.

Kurung, J. N. (1942). The isolation and identification of pathogenic fungi from sputum. Amer. Rev. Tuberc. 46, 365.

Lodder, J. \& Kreger-van Ris, N. J. W. (1952). The Yeasts. A Taxonomic Study. Amsterdam: North Holland Publishing Co.

MAGER, J. \& AschNer, M. (1947). Biological studies on capsulated yeasts. J. Bact. $53,283$.

Menna, M. E. DI (1954). Non-pathogenic yeasts of the human skin and alimentary tract. J. Path. Bact. 68, 89.

Menna, M. E. DI (1955a). A search for pathogenic species of yeasts in New Zealand soils. J. gen. Microbiol. 12, 54.

Menna, M. E. DI (1955b). A quantitative study of air-borne fungus spores in Dunedin, New Zealand. Trans. Brit. mycol. Soc. 38, 119.

Menna, M. E. DI (1957). The isolation of yeasts from soil. J. gen. Microbiol. 17, 678.

Menna, M. E. DI (1958). Biological studies of some tussock grassland soils. 3. Yeasts of three tussock grassland soils. N.Z. J. Agric. Res. 1, 939.

Skinner, C. E. \& HuXley, M. J. (1956). Rhodotorula glutinis. Mycologia, 48, 371.

Uden, N. van \& Do Carmo Sousa, L. (1957). Yeasts from the bovine caecum. J. gen. Microbiol. 16, 385.

Wieringa, K. T. (1955). Der Abbau der Pektine; der erste Angriff der organischen pflanzensubstanz. Z. Pflernähr. Düng. 69, 150.

Wieringa, K. T. (1956). The micro-organisms decomposing pectic substances in the dew retting process of flax. Neth. J. agri. Sci. 4, 204. 